\title{
Correction to: Nitric Oxide/Cyclic GMP-Dependent Calcium Signalling Mediates IL-6- and TNF-a-Induced Expression of Glial Fibrillary Acid Protein
}

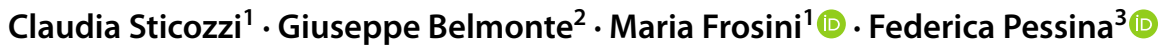

Published online: 12 November 2020

(c) Springer Science+Business Media, LLC, part of Springer Nature 2020

\section{Correction to: Journal of Molecular Neuroscience https://doi.org/10.1007/s12031-020-01708-3}

The original version of this article unfortunately contained a mistake in Fig. 7. Panels $f$ and $g$ were inadvertently missing from the published online version. The update figure is presented below:

The original article can be found online at https://doi.org/10.1007/ s12031-020-01708-3.

Federica Pessina

federica.pessina@unisi.it

1 Department of Life Sciences, University of Siena, Via Aldo Moro 2, 53100 Siena, Italy

2 U.O.C. Anatomia Patologica, Policlinico Santa Maria Alle Scotte, Viale M. Bracci, 16, 53100 Siena, Italy

3 Department of Molecular and Developmental Medicine, University of Siena, Via Aldo Moro 2, 53100 Siena, Italy 
a

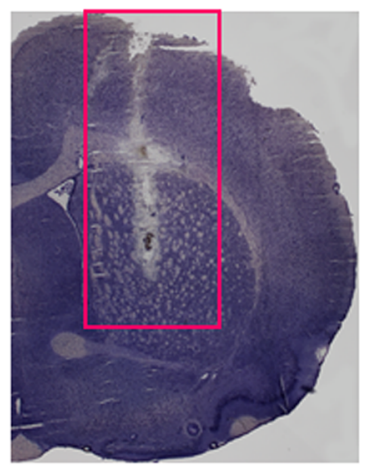

c

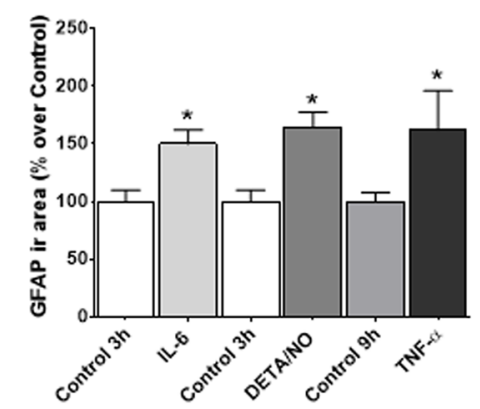

d

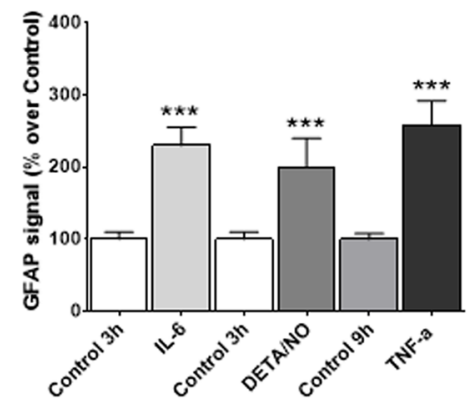

f

$3 \mathrm{~h}$

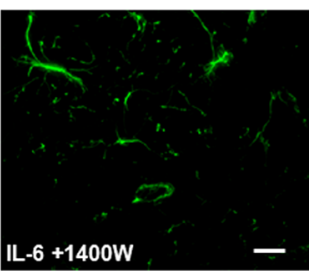

$9 \mathrm{~h}$

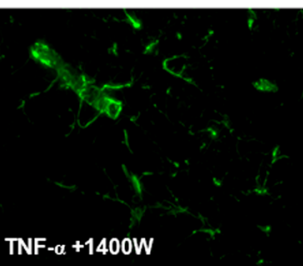

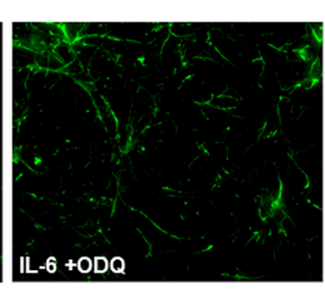

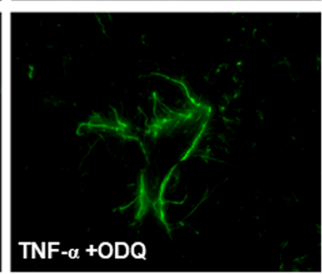

b
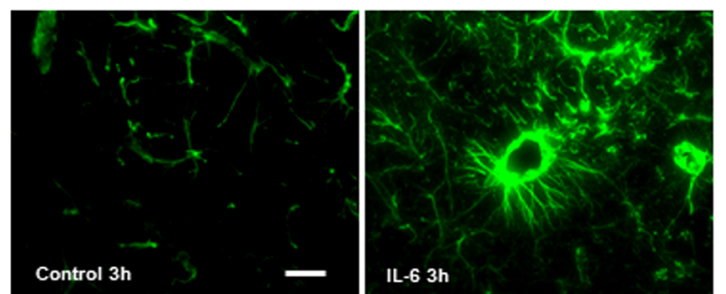

e
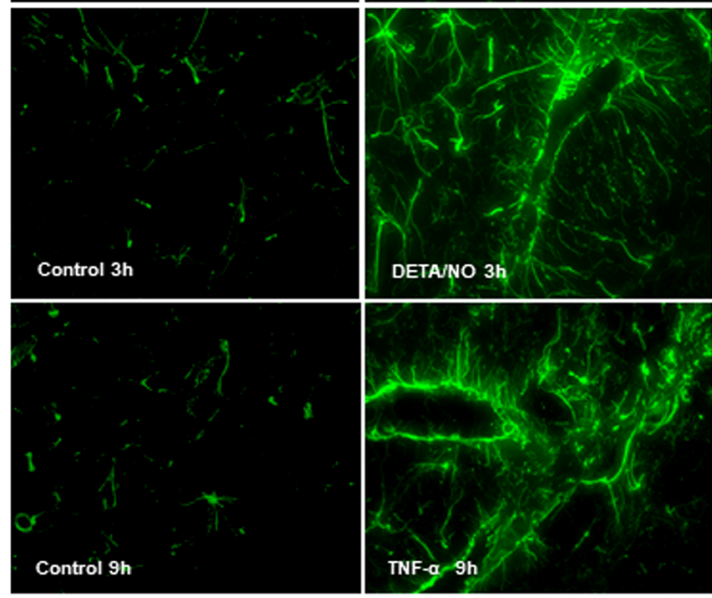

$3 \mathrm{~h}$

$9 \mathrm{~h}$
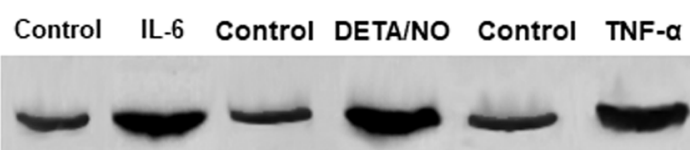

$\beta$-Tubulin
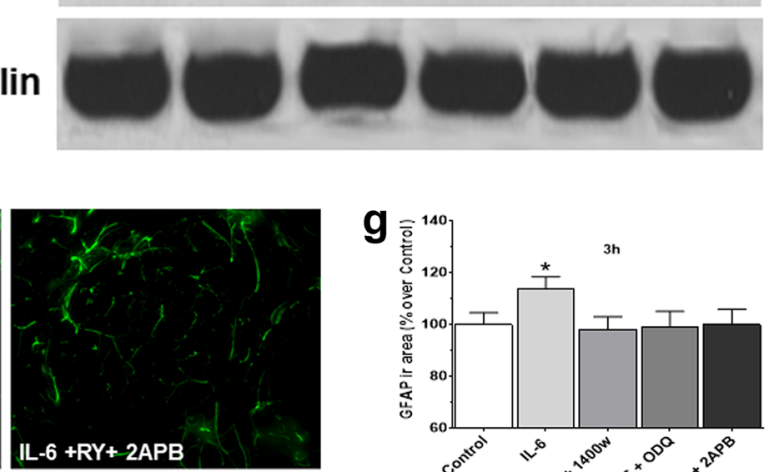

g
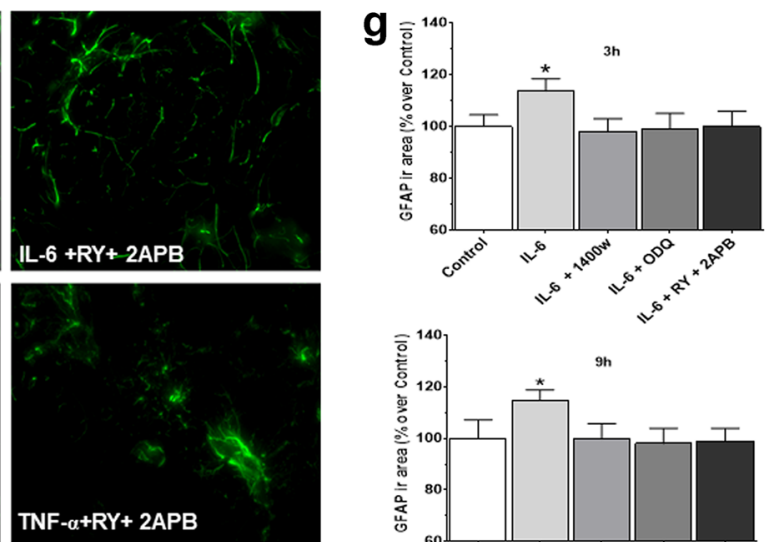

The original article has been corrected.

Publisher's Note Springer Nature remains neutral with regard to jurisdictional claims in published maps and institutional affiliations. 